\title{
VIABILIDADE DO USO DE RESÍDUOS CERÂMICOS NAS CAMADAS DE BASE E SUB- BASE DE PAVIMENTOS FLEXÍVEIS
}

\author{
Maria de Jesus Melo Cerqueira ${ }^{1}$, UNINOVAFAPI \\ Paulo Roberto Nunes de Farias ${ }^{2}$, UNINOVAFAPI \\ Higor Jônathas Sena Dias Lopes ${ }^{3}$, UNINOVAFAPI \\ João da Rocha Marinho Neto ${ }^{4}$, UNINOVAFAPI
}

\section{RESUMO}

Os agregados oriundos da construção civil estão mais escassos, logo é necessário o desenvolvimento de alternativas que venham a substituir estes materiais. Desta maneira, o correto manejo dos materiais provenientes da indústria da construção e demolição tem grande influência em favorecer o reaproveitamento destes resíduos. Uma das alternativas que possui grande potencial para aproveitamento dos resíduos de construção e demolição (RCD) consiste na substituição, em pavimentação de vias urbanas, das camadas de materiais naturais, por RCD devidamente selecionado. Esta pesquisa visa a diminuição na utilização de agregados naturais e de custos relacionados a sua extração e transporte, assim como a minimização de impactos ambientais. Diante desse contexto para a realização desta pesquisa, foi feito um levantamento bibliográfico apresentando estudos e ensaios relativos à aplicação de resíduos cerâmicos como base e sub-base de pavimento. Em virtude dos fatos mencionados, o desenvolvimento de pesquisas e a adoção de ideias para minimizar os impactos causados pela incorreta gestão de materiais na construção civil, como no caso dos resíduos cerâmicos, representam alternativas que podem diminuir os passivos ambientais gerados na cadeia produtiva da indústria da construção.

Palavras-Chave: Resíduos de construção e demolição. Resíduos cerâmicos. Base e sub-base. Pavimentos.

\section{INTRODUÇÃO}

A análise da viabilidade de uso de materiais não convencionais e alternativos para a execução de camadas dos pavimentos flexíveis, tem sido objeto de várias pesquisas que são influenciadas por

\footnotetext{
${ }^{1}$ Graduanda em Engenharia Civil do Centro Universitário UNINOVAFAPI, mariadejesusmelocerqueira@gmail.com.

${ }^{2}$ Graduando em Engenharia Civil do Centro Universitário UNINOVAFAPI, pauloroberto.n.farias@gmail.com.

${ }^{3}$ Engenheiro Civil, Centro Universitário UNINOVAFAPI, higorjonathan@ gmail.com.

${ }^{4}$ Engenheiro Civil, CEUPI, joromaneto@gmail.com 
ANAIS CBCS 2019 | 3 a 5 de outubro de 2019 | Centro Universitário Santo Agostinho - Teresina - PI

alguns fatores, dentre os quais destacam-se as limitações ambientais impostas para a exploração de materiais naturais, fatores econômicos relacionados as distâncias das jazidas e o potencial de utilização dos materiais descartados pelas indústrias (OLIVEIRA, 2007).

O ramo da construção civil, cada vez mais, se caracteriza por ser uma atividade geradora de grandes volumes de resíduos, onde a produção destes está relacionada diretamente aos impactos ambientais. Tendo em vista o modelo de desenvolvimento sustentável, não há mais espaço para a concepção de que os locais de deposição de resíduos e os recursos naturais são infindáveis. Para a minimização destes impactos, políticas ambientais estão sendo debatidas constantemente para que haja uma destinação correta e uma possível reutilização desses rejeitos (REDIVO, 2011).

Segundo Zordan (1997) o alto consumo de matérias-primas está diretamente relacionado ao grande desperdício de materiais que acontece nos empreendimentos, a durabilidade das estruturas construídas e devido às obras de reparos e adaptações das edificações existentes.

Devido a necessidade e demanda, no Brasil, de diversas obras de infraestruturas, como por exemplo rodovias, portos e aeroportos (setores geradores de considerável degradação ambiental) evidencia-se a necessidade da busca da redução dos impactos que estas atividades irão gerar; com este propósito discute-se a viabilidade da utilização de materiais alternativos nestes seguimentos da construção, através do desenvolvimento de novas tecnologias que possam satisfazer, técnica e economicamente, a viabilidade de uso dos resíduos resultantes dessas atividades (BALBO, 2007 apud BAGATINI, 2011, p.23).

Um dos itens de fácil visualização deste desperdício no ramo da construção são os materiais cerâmicos, que possuem grande potencial para um possível reuso, salientando-se, principalmente, seu emprego como agregado. Podem-se apresentar como componentes granulares nas camadas de base e sub-base na pavimentação rodoviária, onde antes deverão passar por um prévio processo de seleção, visando não haver materiais que possam vir a interferir na qualidade e no pleno funcionamento do pavimento (BAGATINI, 2011).

Segundo o manual de pavimentação do DNIT (2006), entende-se por base a camada destinada a resistir e distribuir os esforços oriundos do tráfego e sobre a qual se constrói o 


\section{CONGQEESSOCIENCIAESOCIEDADE

ANAIS CBCS 2019 | 3 a 5 de outubro de 2019 | Centro Universitário Santo Agostinho - Teresina - PI

revestimento asfáltico, e sub-base a camada de pavimentação complementar a esta, quando por circunstâncias técnico-econômicas não for aconselhável construir a base diretamente sobre a camada de subleito ou reforço.

Para amenização dos impactos ambientais gerados pela construção civil se faz necessária a adoção de medidas mitigadoras. Dessa forma, ressalta-se que a utilização de resíduos como componentes da pavimentação, poderá proporcionar, segundo Oliveira (2007):

- Diminuição na utilização de agregados naturais e de custos relacionados a sua extração e transporte;

- Minimização de impactos ambientais;

- Benefícios comerciais com a aplicação dos resíduos;

- Redução dos investimentos necessários para a construção dos pavimentos com materiais convencionais.

\section{METODOLOGIA}

Neste estudo adotou-se como estratégia metodológica a revisão bibliográfica devido a possibilidade de acesso a experiências de autores que já pesquisaram acerca do assunto. Este estudo foi pesquisado na base de dados do Google Acadêmico, com o assunto uso de resíduos cerâmicos nas camadas de base e sub-base em pavimentos. Após as pesquisas, 10 trabalhos foram selecionados para estudo.

\section{RESULTADOS E DISCUSSÃO}

Bagatini (2011) verificou a viabilidade de elementos cerâmicos em camadas de base e subbase em vias urbanas através da construção de uma pista experimental para avaliação estrutural desses componentes, utilizando-se de medidas deflométricas com a viga de Benkelman. $\mathrm{O}$ autor afirmou que de acordo com o tráfego da via a ser implementada há a viabilidade de utilização dos resíduos cerâmicos. 
ANAIS CBCS 2019 | 3 a 5 de outubro de 2019 | Centro Universitário Santo Agostinho - Teresina - P

Redivo (2011) em sua pesquisa "Utilização de Resíduo Cerâmica Vermelha em Misturas com Solo para a Construção de Camadas de Pavimentos com Baixo Volume de Tráfego" utilizou-se de misturas solo-agregado para três tipos de solos diferentes e que foram submetidos aos ensaios tradicionais de pavimentação, e aos ensaios da metodologia MCT, ao término destes testes o autor constatou que as misturas apresentaram comportamentos diversos, que variaram de acordo com as dosagens dos materiais utilizados, porém foram satisfatórios a eventual utilização. Chegando à conclusão de que os resíduos de cerâmica vermelha podem ser utilizados em misturas de solo, na construção de camadas de pavimentos com baixo volume de tráfego

Através deste estudo comprova-se que os agregados reciclados provenientes de resíduos cerâmicos de obra possuem características similares ou próximas aos agregados comumente utilizados na pavimentação, e que em substituição parcial do material granular das camadas inferiores do pavimento estão condizentes com as normatizações adotadas pelo DNIT.

Com o levantamento bibliográfico realizado, comprovou-se viabilidade técnica de utilização destes agregados para a produção de pavimentos flexíveis, devido às suas propriedades alcançadas e, também, a viabilidade econômica tendo em visto que o custo de produção dos mesmos é bastante inferior ao custo de produção do agregado natural.

\section{CONCLUSÕES}

A busca pelo modelo de desenvolvimento sustentável, fez com que o trabalho abordasse aspectos relacionados a utilização dos resíduos de construção e demolição (RCD), e o possível aproveitamento destes que de forma geral são descartados no meio ambiente, em camadas de base e sub-base pavimentos.

Os resultados deste levantamento indicam que é viável a utilização de agregados reciclados de origem cerâmica oriundos de descarte da construção civil, se tornando uma interessante alternativa ao emprego de agregados de origem natural que são amplamente utilizados nas camadas estruturais da pavimentação. 
ANAIS CBCS 2019 | 3 a 5 de outubro de 2019 | Centro Universitário Santo Agostinho - Teresina - P

Por fim, salienta-se que essa forma de reciclagem e reutilização dos agregados cerâmicos pode contribuir para a o aumento da vida útil de aterros devido a diminuição do descarte dos resíduos de construção e demolição $(R C D)$, havendo também a minimização de impactos ambientais oriundos da extração agregados de origem natural, por conseguinte contribuindo para um desenvolvimento sustentável.

\section{REFERÊNCIAS}

BAGATINI, Felipe. Resíduos de construção civil: Aproveitamento como base e sub-base na pavimentação de vias urbanas. 2011. 72 f. TCC (Graduação) - Curso de Engenharia Civil, Departamento de Engenharia Civil, Universidade Federal do Rio Grande do Sul, Porto Alegre, 2011.

CONSELHO NACIONAL DO MEIO AMBIENTE. Brasília. 2002. Resolução CONAMA no 307, de 5 de julho de 2002. Disponível em:< http://www.mma.gov.br/port/conama/legiabre.cfm?codlegi=307>. Acesso em: 15 de nov. 2017.

DIAS, João Fernando. Avaliação de resíduos da fabricação de telhas cerâmicas para seu emprego em camadas de pavimento de baixo custo. 2004. 268 f. Tese (Doutorado) - Curso de Engenharia Civil, Universidade de São Paulo, São Paulo, 2004.

DNIT (2006). Manual de pavimentação. Publicação IPR - 179. Ministério dos transportes. Departamento nacional de infraestrutura de transportes, Instituto de pesquisas e rodovias.

GRUBBA, David Christian Regis Pereira. Estudo do comportamento mecânico de um agregado reciclado de concreto para utilização na construção rodoviária. 2009. 163 f. Dissertação (Mestrado) - Curso de Engenharia Civil, Escola de Engenharia de São Carlos, Universidade de São Paulo, São Carlos, 2009.

OLIVEIRA, João Carlos de. Indicadores de potencialidades e desempenho de agregados reciclados de resíduos sólidos da construção civil em pavimentos flexíveis. 2007. 190 f. Tese (Doutorado) Curso de Engenharia Civil, Departamento de Engenharia Civil e Ambiental, Universidade de Brasília, Brasília, 2007.

REDIVO, Israel Maccari. Utilização de resíduo de cerâmica vermelha em misturas com solo para construção de camadas de pavimentos com baixo volume de tráfego. 2011. 160 f. Dissertação 
ANAIS CBCS 2019 | 3 a 5 de outubro de 2019 | Centro Universitário Santo Agostinho - Teresina - P |

(Mestrado) - Curso de Engenharia Civil, Universidade Federal de Santa Catarina, Florianópolis, 2011.

ZORDAN, S. E. A utilização do entulho como agregado, na confecção do concreto. Campinas. 1997. 140p. Dissertação (Mestrado) - Faculdade de Engenharia Civil, UNICAMP. 